УДК 159.99

DOI: $10.18384 / 2310-7235-2015-3-17-22$

\author{
Гайдамашко и.В. \\ Московский государственный областной университет \\ Посохова А.B. \\ Институт международной торговли и права (г. Москва) \\ ПРОБЛЕМА ПСИХОЛОГИЧЕСКОЙ ГОТОВНОСТИ \\ К ПРЕДПРИНИМАТЕЛЬСКОЙ ДЕЯТЕЛЬНОСТИ
}

Аннотация. В статье представлены результаты исследований психологической готовности к предпринимательской деятельности в контексте обеспечения конкурентоспособности предпринимателей. Проанализировано содержание психологической готовности с точки зрения предпринимательской деятельности в условиях конкурентной среды. Представлены результаты эмпирических исследований, устанавливающих корреляционные связи между компонентами психологической готовности и личностно-профрессиональными качествами предпринимателей. Показано, что психологическая готовность к предпринимательской деятельности обеспечивает ее успешность и конкурентоспособность.

Ключевые слова: конкурентоспособность, профессиональная готовность, психологическая готовность, личностно-профессиональные качества, корреляционные связи.

\author{
I. Gaydamashko \\ Moscow State Regional University \\ A. Posokhova \\ Institute of International Trade and Law, Moscow
}

\title{
THE PROBLEM OF PSYCHOLOGICAL READINESS FOR BUSINESS
}

Abstract. The article presents the results of studies of psychological readiness for entrepreneurship in the context of the competitiveness of businesses. The content analysis of psychological readiness in terms of business in a competitive environment is done. The results of empirical studies that establish correlations between the components of psychological readiness and personal-professional qualities of entrepreneurs are given. It is shown that psychological readiness for business ensures its success and competitiveness.

Key words: competitiveness, professional readiness, psychological readiness, personal-professional qualities, correlations.

\section{Психологические исследования предпринимательской деятельно- сти, проведенные в последние годы (И.В. Антоненко, А.В. Бояринцева, Н.Н. Глушач, Е.А. Ермолаева, Е.К. Кли-}

(с Гайдамашко И.В., Посохова А.В., 2015. мова, О.Н. Козлова, В.П. Позняков и др.), убедительно свидетельствуют, что данная деятельность является сложно совмещенной и отличается рядом психологических особенностей. В частности, она осуществляется: 
- в условиях постоянной и острой конкуренции;

- при действии различных негативных экстремальных факторов (риски, недобросовестная конкуренция, перегрузки, сильные стрессы, угрозы и даже опасность), в основном направленных на самого субъекта предпринимательской деятельности [2];

- при ощутимой зависимости от внешних факторов, значительная часть которых трудно прогнозируется [4].

Этими особенностями обусловливается частое возникновение у предпринимателей негативных функциональных состояний (высокой непродуктивной психической напряженности, утомления и пр.), связанных с большими психоэнергетическими затратами, что негативно сказывается на регуляции их деятельности, снижает их внутреннюю ресурсность.

Сказанное свидетельствует о том, что с психологической точки зрения многие предприниматели осуществляют свою деятельность в так называемых особых, а часто и в экстремальных условиях. Регуляция деятельности в таких условиях, как показали проведенные исследования, существенно отличается от ее регуляции в нормальных условиях [3, с. 27]. Это необходимо учитывать при подготовке к предпринимательской деятельности.

Отмеченные отличительные особенности предпринимательской деятельности требуют обязательного формирования профессиональной и психологической готовности к ней, что является необходимым условием ее эффективности и обеспечивает конкурентоспособность.

Иными словами, предприниматель должен не только знать, каково психо- логическое содержание деятельности в условиях острой конкуренции и действия экстремальных факторов, но и быть готовым к ней (психологически и на уровне умений), формировать соответствующий психологический настрой. В этом случае отмеченные негативные условия и факторы не дезорганизуют предпринимательскую деятельность и взаимодействия.

Следует отметить, что психологическая готовность к предпринимательской деятельности, особенно как составная часть или условие ее конкурентоспособности, пока не стала объектом систематизированных психологических исследований. Недостаточная разработанность данной проблемы при высокой научной и практической значимости обусловливают актуальность таких исследований [1].

Изучение психологической готовности к предпринимательской деятельности как условия или составной части конкурентоспособности должно базироваться на психологических исследованиях общей профессиональной и психологической готовности. В данных работах профессиональная готовность исследовалась как проявление инструментальной (знания, опыт, умения, навыки, позволяющие эффективно выполнять профессиональную деятельность) и собственно психологической (мотивационная готовность, уверенность в способности справиться с заданием, адекватная мобилизация, настрой на успешное решение профессиональных задач) готовности. Отмечалось, что без соответствующей инструментальной готовности трудно сформировать готовность психологическую, поэтому инструменталь- 
ная готовность является базовой для формирования и развития психологической готовности (Н.Д. Завалова, В.А. Пономаренко).

В связи с особой важностью для регуляции деятельности и ее эффективности психологическая готовность стала объектом специальных исследований. Было установлено, что психологическая готовность может так же, как и профессиональная готовность, быть постоянной (долговременной) и кратковременной (в виде настроя). Причем наличие постоянной психологической готовности не исключает необходимости формировать соответствующий настрой в конкретных ситуациях. В предпринимательской деятельности важную роль играют все отмеченные виды психологической готовности.

В психологических исследованиях (О.Б. Дмитриева, В.Г. Зазыкин, А.А. Касабов, Г.С. Михайлов и др.) было показано, что психологическая готовность является важной составляющей профессионализма личности и деятельности. При этом сущностная характеристика психологической готовности обусловливается способностью мобилизовать внутренние ресурсы, связывается с психической устойчивостью, уровнем произвольной саморегуляции, уровнем информационного и инструментального обеспечения деятельности (В.А. Бодров, Н.Д. Завалова, А.В. Карпов, В.Т. Мышкина, Л.С. Нерсесян и др.), а также с направленностью субъекта на деятельность, учитывающую его психологические установки, интересы, жизненный опыт, ценностное отношение к профессии (А.А. Деркач, Н.В. Кузьмина, В.А. Сластенин и др.). Психологи- ческая готовность зависит также от полноты и качества представлений об условиях и характере осуществляемой деятельности.

Важным видом психологической готовности, особенно значимым для предпринимательской деятельности, является готовность к экстренным действиям в ситуации неопределенности и действия трудно прогнозируемых экстремальных факторов (О.А. Конопкин, Л.С. Нерсесян и др.). Она проявляется в способности адекватно и быстро реагировать на возникновение экстренных факторов. Готовность к экстремальным ситуациям является синтезом (или особым органичным сочетанием) долговременной психологической готовности, опыта и настроя и зависит от уровня произвольной саморегуляции, опыта, направленности на такую деятельность и ряда других психологических факторов [8].

Проведенный анализ состояния проблемы исследования показал, что, если у предпринимателя не сформирована психологическая готовность, его деятельность не будет результативной и конкурентоспособной. Это может свидетельствовать также и о преждевременности включения субъекта в предпринимательскую деятельность.

Отмеченные теоретические предпосылки стали основой для эмпирического исследования психологической готовности к предпринимательской деятельности в контексте обеспечения конкурентоспособности предпринимателей. Их целью являлось выявление психологических коррелят психологической готовности, а также психологических факторов, оказывающих на нее значимое влияние. 
Объектом исследования была выбрана студенческая молодежь, обучающаяся по специальностям экономика, маркетинг и менеджмент. Количество обследованных было 134 человека (студенты разных курсов, обучающихся по специальности менеджмент и экономика в КГУ им. Циолковского и Калужском филиале РАНХ и ГС). Важно отметить и то, что большинство респондентов предполагают в будущем работать в коммерческих организациях, а некоторые из них уже в них работают.

В данном эмпирическом исследовании использовались следующие методы:

- анкетный опрос (по анкете, разработанной для изучения психологической готовности к предпринимательской деятельности) [7, с. 87];

- 16 PF;

- методика «Диагностика психологической готовности к предпринимательской деятельности» Е.К. Климовой [5].

Методика Е.К.Климовой представляет собой опросник, включающий шкалы, соответствующие теоретической модели психологической готовности к предпринимательской деятельности. В этой модели психологическая готовность к предпринимательской деятельности позиционировалась как сложный функционал, включающий следующие компоненты: предпринимательские мотивы, предпринимательские цели, предприимчивость, стратегичность и прогностичность мышления, стрессоустойчивость, предпринимательские интенции, предпринимательские ресурсы, психологический настрой. При применении данной методики можно получить как целостную оценку психологической готовности, так и определить содержание ее факторной структуры.

Психологическая готовность к предпринимательской деятельности в данном исследовании позиционировалась как условие и как составная часть их конкурентоспособности, которая, в свою очередь, рассматривалась как детерминанта их профессиональной успешности [6, с. 65].

Остановимся на качественной интерпретации полученных в эмпирическом исследовании результатов.

Проведенное эмпирическое исследование показало, что в представлениях респондентов содержание психологической готовности к предпринимательской деятельности как условия конкурентоспособности и ее составляющей респондентами связывалось:

- с высоким уровнем психологических личностно-профессиональных качеств (активности, мобильности, гибкости, оперативности, психической устойчивости, мотивации на успех и др.);

- со способностью мобилизовать свои личностные и профессиональные ресурсы, настроить себя на успешную деятельность (особая роль отводилась саморегуляции, умению пополнять свои ресурсы);

- с опытом и умениями эффективно взаимодействовать.

Примерно треть респондентов психологическую готовность к предпринимательской деятельности в условиях острой конкуренции связывали с уровнем профессионализма предпринимателей.

Важным было мнение респондентов относительно связи психологической 
готовности к конкурентной деятельности и их конкурентоспособности. Мнения респондентов разделились примерно поровну. Одна часть респондентов считала, что психологическая готовность является необходимым условием конкурентоспособности предпринимателей, а связь существует линейная пропорциональная. Другая часть полагала, что психологическая готовность является составной частью конкурентоспособности и связь тоже линейная пропорциональная. В дискуссии по результатам исследований респонденты отметили, что психологическая готовность является и тем и другим психологическим свойством предпринимателей. Отмеченные варианты позиционирования не связаны с психологическими механизмами психологической готовности, а обусловлены теоретическим ракурсом ее рассмотрения.

По мнению подавляющего большинства респондентов, формирование психологической готовности к конкурентной деятельности как составляющей конкурентоспособности возможно в процессе обучения профессии предпринимателя. Большая роль отводилась опыту практической деятельности.

Проведенное психологическое тестирование и применение методики Е.К. Климовой позволили осуществить корреляционный анализ. В процессе корреляционного анализа с помощью критерия Спирмена установлены статистически значимые связи (при $\mathrm{p}<0,05)$ между отдельными составляющими психологической готовности личностно-профессинальными свойствами и представлениями о конкурентоспособности $(\mathrm{r}=0,38-0,62)$.
В частности, важным детерминирующим фактором психологической готовности оказались мотивы предпринимательской деятельности и предпринимательские интенции. Это, по мнению респондентов, должно быть главным стимулом развития всех видов психологической готовности как личностно-профессионального свойства предпринимателей.

Психологическая готовность к предпринимательской деятельности, как показали результаты корреляционного анализа, прямо зависит от имеющихся у предпринимателей ресурсов и индивидуального личностного и предпринимательского потенциала. Особую роль здесь играют предпринимательские способности и направленность на предпринимательскую деятельность.

Предприимчивость связывалась со стратегическим мышлением, предпринимательскими интенциями, расчетливостью и открытостью для контактов и взаимодействий. В свою очередь стратегическое мышление коррелировало со способностью строить точные и дальние прогнозы.

Устойчивость к профессиональным стрессам имела корреляционные связи с эмоциональной стабильностью, уровнем произвольной саморегуляции и опытом предпринимательской деятельности.

Характеристика смелости коррелировала с предприимчивостью и кратковременной психологической готовностью (настроем).

Самостоятельность связывалась с расчетливостью и долговременной психологической готовностью.

Уровень собственной психологической готовности к предприниматель- 
ской деятельности коррелировал с представлениями респондентов относительно психологической сущности и содержания конкурентоспособности и самой готовности как личностно-профессионального свойства предпринимателей.

В целом психологическая готовность коррелирует также со смелостью, самостоятельностью, эмоциональной стабильностью, хорошими представлениями о будущей деятельности.

Из представленных результатов видно, что респонденты обладают хорошими предпринимательскими ресурсами и интенциями, т.е. направленностью сознания и мышления на предпринимательскую деятельность. Весьма высоки и самооценки психологической готовности к предпринимательской деятельности в условиях конкуренции, причем такие самооценки являются обоснованными.

Среди личностно-профессиональных свойств, обеспечивающих высокий уровень психологической готовности к предпринимательской деятельности, наиболее сильное влияние оказывают предпринимательские способности и потенциал, предпринимательские интенции, направленность на данную деятельность.

Следует отметить, что полученные в результате проведенных исследований личностные и профессиональные корреляты психологической готовности к предпринимательской деятельности являются также коррелятами конкурентоспособности предпринимателей. Об этом свидетельствует сопоставление психологического содержания конкурентоспособности с выявленными коррелятами психоло- гической готовности к предпринимательской деятельности.

Полученные в проведенном исследовании результаты обусловили необходимость и содержание дальнейших исследований психологической готовности к предпринимательской деятельности.

\section{ЛИТЕРАТУРА:}

1. Гайдамашко И.В., Пугачева Е.В., Жемерикина Ю.И. Конкурентная среда - основной фактор влияния на процесс допрофессионального развития человека // Человеческий капитал, 2014. № 3(63). C. $40-45$.

2. Гайдамашко И.В., Селезнев В.Н., Сысоев В.В. Подготовка антикризисных менеджеров методами психологического анализа профессиональной деятельности // Вестник Московского государственного областного университета. Серия: Психологические науки, 2012. № 2. С. 155-163.

3. Деркач А.А., Зазыкин В.Г. Профессионализм деятельности в особых и экстремальных условиях. М., 2003. 227 с.

4. Завьялова Е.К., Посохова С.Т. Психология предпринимательства. СПб., 1997. 197 с.

5. Климова Е.К. Профессиональная деятельность предпринимателя. СПб. 2014. 208 c.

6. Посохова А.В. Конкурентоспособность предпринимателей: результаты психолого-акмеологического исследования // Человеческий капитал. 2014. № 8(68). С. 64-67.

7. Посохова А.В. Психологическая готовность к предпринимательской деятельности как условие конкурентоспособности // Экономические и социально-гуманитарные исследования. 2015. № 1 (5). С. 85-90.

8. Щербина А.В. Формирование психологической готовности к деятельности в экстремальных управленческих ситуациях. М., 1997. 136 с. 